\title{
Los anticuerpos anti-péptidos citrulinados cíclicos serían útiles para el diagnóstico de artritis reumatoidea
}

Anti-Cyclic Citrullinated Peptide could be useful for the diagnosis of Rheumatoid Arthritis

Nishimura K y col. Ann Intern Med, 2007; 146:797-808

\section{Objetivo}

Determinar si los anticuerpos anti péptidos citrulinados (ant CCP) identifican con mayor precisión pacientes con artritis reumatoidea $(A R)$ y predicen mejor el daño radiológico que el factor reumatoideo (FR).

\section{Método y fuente de datos}

Estudios de más de nueve participantes con AR conocida 0 sospechada de menos de un año de duración, usando como referencia los criterios del Colegio Americano de Reumatología (ACR) de 1987 publicados en MEDLINE (1987-2006).

\section{Análisis de datos}

Modelo que combina estimaciones de sensibilidad, especificidad y coeficientes de probabilidad positivos y negativos (CP+y $(\mathrm{CP}-)^{*}$. El análisis se estratificó por generación de anti CCP (CCP-1 y CCP-2) subtipo de FR (IgM, IgG e IgA) y por la precocidad del diagnóstico de AR. Se evaluó la heterogeneidad* entre los estudios y la posibilidad de sesgo de publicación*.

\section{Resultados}

De 302 trabajos, fueron seleccionados 37 sobre anticuerpos anti CCP y 50 sobre FR (la mayoría no explicitó la ceguera de los investigadores sobre la valoración clínica). Ver los principales resultados en la tabla 1.
Tabla 1: características operativas de los anticuerpos anti péptidos citrulinados y el factor reumatoideo en artritis reumatoidea.

\begin{tabular}{|c|c|c|c|c|}
\hline \multirow{2}{*}{$\begin{array}{l}\text { Tipo de } \\
\text { anticuerpo }\end{array}$} & \multirow{2}{*}{$\begin{array}{c}\text { Sensibilitad } \\
(\text { (B95\%) }\end{array}$} & \multirow{2}{*}{$\begin{array}{c}\text { Especificidad } \\
(\mathrm{L} 95 \% \%)\end{array}$} & \multicolumn{2}{|c|}{ Coeficiente de Probabilidad } \\
\hline & & & & \\
\hline & & & & \\
\hline & $69^{\circ}$ & 85 & $4,86(3,95-5,97)$ & $0,38(0,33-0,44$ \\
\hline
\end{tabular}

Los anti CCP-2 fueron marcadores más sensibles que los anti CCP-1. Tres de cuatro estudios encontraron que el riesgo de progresión radiológica fue mayor en los pacientes con anticuerpos anti CCP positivos, que en los pacientes con FR IgM positivos.

\section{Conclusiones del estudio}

Los anticuerpos anti CCP son más específicos que el FR para el diagnóstico de AR, predicen mejor el daño radiológico y deberían incluirse en los criterios diagnósticos de AR.

Palabras Clave: artritis reumatoidea, factor reumatoideo, anti-péptidos citrulinados cíclicos.

Keywords: Anti-Cyclic Citrullinated Peptide, Rheumatoid Factor, Rheumatoid Artritis Fuente de financiamiento: subsidios o becas de investigación para jóvenes cientificos a cargo del gobierno de Japón.

\section{Comentario}

La AR afecta al 1\% de la población mundial' siendo importante el diagnóstico temprano por la rápida destrucción articular e incapacidad funcional que provoca en los primeros meses de la enfermedad ${ }^{2,3}$. El FR es un marcador inespecífico ${ }^{4}$, mientras que los anti CCP fueron desarrollados en un intento de mejorar su especifidad ${ }^{5}$. Los anti CCP, que podrían tener un rol etiopatogénico, definen un fenotipo caracterizado por daño estructural severo, discapacidad funcional y beneficio con tratamiento muy temprano ${ }^{6}$ que permitiría cambiar el curso natural de la enfermedad?. En la práctica clínica, la mayoría de los reumatólogos recomienda medir ambos para maximizar la sensibilidad y por que el FR está incluido en los criterios diagnósticos. Si bien identificamos tres tipos de sesgos* en esta revisión: 1) de publicación* (resultados favorables de los anti CCP); 2) de incorporación* (FR es un criterio diagnósticosd de AR); 3) de búsqueda bibliográfica* (sólo se utilizó MEDLINE); intentaremos dar una guía sobre cuándo medir anti CCP y/o FR. Si la probabilidad de AR es relativamente baja (ej. monoartritis de rodilla un paciente atendido en un centro de atención primaria) medir anti CCP sería una estrategia razonable para reducir los falsos positivos. Si es alta (ej. sinovitis de manos y carpos en centros de atención reumatológica o reúne criterios diagnósticos) tanto los anti CCP como el FR serían de utilidad diagnóstica.

\section{Conclusiones del comentador}

Los anticuerpos anti CCP son más específicos para el diagnóstico de AR, en especial AR temprana. Su presencia debe ser interpretada con precaución en la luz de la probabilidad pretest*, 10 que requiere experiencia clínica. También predicen mejor el daño radiológico y deberían incluirse en las pruebas diagnosticas y entre los criterios diagnósticos de la AR.

Javier Rosa, Médico [ Adscripto Sección Reumatología, Servicio de Clínica Médica, Hospital Italiano de Buenos Aires. ]

Rosa J. Los anticuerpos anti-péptidos citrulinados cíclicos serían útiles en el diagnóstico de artritis reumatoidea. Evid. actual. práct. ambul; 10(5):143, Sep-Oct. 2007. Comentado de: Nishimura K, Sugiyama D, Kogata Y, Tsuji G, Nakazawa T, Kawano S, Saigo K, Morinobu A, Koshiba M, Kuntz KM, Kamae I, Kumagai S. Meta-analysis: diagnostic accuracy of anti-cyclic citrullinated peptide antibody and rheumatoid factor for rheumatoid arthritis. Ann Intern Med. 2007 Jun 5;146(11):797-808. PMID: 17548411.

\section{Bibliografía}

1. Lee DM, et al. Rheumatoid Arthritis. Lancet. 2001; 358:903-11.

2. Landewé R. The benefits of early treatment in rheumatoid arthritis confounding by indication, and the issue of timing (Editorial). Arthritis rheum. 2003; $48: 1-5$. 3. Lard L, et al. Early versus delayed treatment in patients with recent-onset rheumatoid artrhitis: comparison of two cohorts who received different treatment strategies. Am $\mathrm{J}$ Med 2001; 111:446-51.

4. Domer T, et al. Rheumatoid Factor revisited. Curr Opin Rheumatol. 2004: 16:246-53.

5. Schellegens $\mathrm{G}$ et al. The diagnostic properties of rheumatoid artrhitis antibodies recognizing a cyclic citrullinated peptide. Artrhitis Rheum. 2000; 43:155-63.

5. Schelegens Ge Haze Ann Intern Med. 2007; 146:816-7.

6. Finckh A, et al. Anti Cyclic Citrullinated Peptide Antibodies in the Diagnosis of Rheunatoid Artritis. Bayes Clears the Haze Ann ling Commitee for International Clinical Studies 7. Combe B, et al. EULAR recommendations for the management of
Including Therapeutics (ESCISIT). Ann Rheum Dis. 2007; 66:34-45. 